\title{
ANALISIS SIFAT MEKANIK PIPA CARBON STEEL GRADE A A106 DAN GRADE B A53 UNTUK PROSES PRODUKSI PADA KILANG LNG
}

\author{
Media Nofri ${ }^{1}$, Arif Fardiansyah ${ }^{2}$ \\ 1,2 Program Studi Teknik Mesin S1, Fakultas Teknologi Industri, Institut Sains dan Teknologi Nasional, Jakarta \\ email : medi.bagindo@gmail.com
}

\begin{abstract}
This study aims to determine the quality and mechanical properties of carbon steel pipes for the production process at a good liquefied Liquified Natural Gas and after 10 years of use. As a temporary repair reference on damaged pipe. The step is to compare the results of testing the mechanical properties and microstructure of both types of pipes. The parameters used are chemical composition, hardness, tensile strength, and micro structure of both types of pipes. Test results on a good pipe have an average hardness value of $90 \mathrm{HV}$ whereas in the damaged pipe the average hardness value of $85.9 \mathrm{HV}$ decreased by $4.1 \mathrm{HV}$. The tensile test on a good pipe value of $60 \mathrm{~kg} / \mathrm{mm} 2(588 \mathrm{MPa})$, on a damaged tube of tensile strength of $56 \mathrm{~kg} / \mathrm{mm} 2(549$ $\mathrm{MPa})$, decreased $4 \mathrm{~kg} / \mathrm{mm} 2(39 \mathrm{MPa})$. Good pipe microstructure test results consist of ferrite and pearlite structures while in the damaged pipe consisting of pearlite phase. From the results of the study concluded that the pipeline after the use for 10 years experienced a decrease in mechanical properties, namely: hardness and tensile strength. This is the result of thinning of the corrosion pipe wall thickness.
\end{abstract}

Keywords: Carbon Steel, Uji Tarik, Uji Kekerasan, Uji Metallography.

\section{PENDAHULUAN}

Sifat mekanik terdiri dari keuletan, kekerasan, kekuatan, dan ketangguhan, sifat mekanik merupakan acuan untuk melakukan proses selanjutnya terhadap suatu material. Proses lanjut terhadap suatu material yang dimaksudkan adalah proses pembentukan dengan menggunakan proses permesinan, untuk mengetahui sifat mekanik pada suatu logam maka perlu dilakukannya pengujian terhadap logam tersebut. Salah satu pengujian yang dilakukan adalah pengujian tarik dan pengujian komposisi kimia.

Dalam pembuatan suatu kontruksi diperlukan material sesuai dengan standard yang digunakan. Sebagai contoh dalam pembuatan kontruksi sebuah instalasi proses produksi minyak dan gas alam diperlukan material yang kuat untuk menerima beban dan tegangan yang diterima oleh material. Material juga harus elastis agar pada saat terjadi pembebanan standar atau berlebih tidak mengalami patah, Salah satu contoh material yang banyak digunakan untuk kontruksi instalasi proses produksi minyak dan gas alam adalah baja karbon.

Material yang akan di analisis adalah pipa baja karbon dengan komposisi karbon $\mathrm{C}<0,25 \%$ dan unsur penyusun utamanya terdiri dari besi $(\mathrm{Fe})$, dan karbon (C), serta unsur-unsur lain seperti: $\mathrm{Mn}, \mathrm{Si}$, $\mathrm{Ni}, \mathrm{Cr}, \mathrm{V}$ yang tersusun dalam persentase yang sangat kecil. Unsur-unsur tersebut sangat menunjang sebuah material untuk memiliki kekuatan dan kekerasan yang baik jika digunakan sesuai standar. Adapun spesifikasi yang dipersyaratkan dalam aplikasinya sebagai bahan baku untuk pipa transmisi gas alam adalah harus memenuhi API $5 L$. Untuk itu perlu dilakukan pengujian untuk memenuhi kedua persyaratan spesifikasi tersebut baik secara mekanik maupun struktur mikronya.

Dari hasil pengujian akan diperoleh sebuah solusi untuk pemilihan material instalasi system pemipaan pada jalur gas alam apakah pipa dengan material Grade A A106 dan Grade B A53 mampu menahan tekanan tinggi. Maka dari itu diperlukannya pengujian tarik dan pengujian komposisi kimia pada material baja karbon Grade A A106 dan baja karbon Grade B A53.

Berdasarkan latar belakang yang telah di uraikan, maka objek yang akan dikaji dalam penelitian ini yaitu : Melakukan analisis sifat mekanik pipa yang terbuat dari baja karbon grade A 106 dan baja karbon grade B A53 yang nantinya akan digunakan untuk proses prdouksi gas alam pada PT.X.

Batasan untuk penelitian ini adalah:

1. Penelitian dilakukan pada material carbon steel grade A A106 dan carbon steel grade B A53 karena material jenis ini memiliki sifat (workability) yang baik, mudah diperoleh, dan harganya relatif lebih murah. 
2. Metode yang digunakan meliputi pengujian komposisi kimia, pengujian tarik, pengujian kekerasan Rockwell dan pengujian metallografi.

Dari uraian tentang latar belakang dan batasan masalah maka penelitian ini bertujuan:

1. Mengetahui kekuatan tarik dan kekerasan pada material carbon steel grade A A106 dan grade B A53.

2. Mengetahui komposisi kimia material carbon steel grade A A106 dan grade B A53.

3. Mengetahui struktur mikro pada material carbon steel grade A A106 dan grade B A53.

\section{TINJAUAN PUSTAKA \\ Baja Karbon}

Baja merupakan paduan yang terdiri dari unsur besi $(\mathrm{Fe})$, karbon $(\mathrm{C})$, dan unsur lainnya. Baja dapat dibentuk melalui pengecoran, pencanaian, atau penemperan. Karbon (C) merupakan salah satu unsur terpenting karena dapat meningkatkan kekerasan dan kekuatan baja. Baja merupakan logam yang paling banyak digunakan dibidang teknik dalam bentuk pelat, pipa, batang, profil dan sebagainya. Secara garis besar baja dapat dikelompokan menjadi dua yaitu baja karbon dan baja paduan. Baja kabon terbagi menjadi tiga macam yaitu: Baja karbon rendah $(<0,25 \% \mathrm{C})$, Baja karbon sedang $(0,25$ $0,55 \%)$, Baja karbon tinggi $(>0,55 \%)$. Sedangkan baja paduan terdiri dari baja rendah dan baja paduan tinggi . Penggunaan baja berbeda-beda berdasarkan kandungan unsur paduan karbon.

\section{Klasifikasi Baja Karbon}

Baja merupakan paduan yang sebagian besar terdiri dari unsur besi dan karbon $0.25 \%$ - 1,7\%. Selain itu baja juga mengandung unsur-unsur lain seperti Sulfur (S), Fosfor (P), Silikon (Si), Mangan (Mn), dan Vanadium. Baja dibagi menjadi 3 (tiga) kategori yaitu :

\section{a. Baja Karbon Rendah}

Baja karbon rendah merupakan baja dengan kandungan unsur karbon dalam struktur baja kurang dari $0,25 \% \mathrm{C}$,

Baja karbon rendah memiliki ketangguhan aus yang rendah. Baja ini tidak dapat dikeraskan karena kandungan karbonnya tidak cukup untuk membentuk struktur martensit.

b. Baja Karbon Sedang

Baja karbon sedang merupakan baja karbon dengan persentase kandungan karbon pada besi sebesar $0,25 \% \mathrm{C}-0,55 \%$ C. Baja karbon sedang memiliki kelebihan bila dibandingkan dengan baja karbon rendah, baja karbon sedang memiliki sifat mekanis yang lebih kuat dengan tingkat kekerasan yang lebih tinggi dari pada baja karbon rendah.
Besarnya kandungan karbon yang terdapat dalam besi memungkinkan baja untuk dapat dikeraskan dengan memberikan perlakuan panas (heat treatment) yang sesuai.

c. Baja Karbon Tinggi

Baja karbon tinggi adalah baja yang memiliki kandungan karbon sebesar $0,55 \% \mathrm{C}-1,7 \% \mathrm{C}$. Baja karbon tinggi memiliki sifat tahan panas, kekerasan serta kekuatan tarik yang sangat tinggi akan tetapi memiliki keuletan yang lebih rendah sehingga baja karbon ini menjadi lebih getas.

\section{Pengaruh Unsur Paduan pada Baja}

Pengaruh unsur paduan pada baja merupakan salah satu hal yang sangat penting untuk diketahui. Pada baja karbon selain unsur besi dan karbon, terdapat pula kandungan unsur lainnya dengan persentase yang berbeda-beda sesuai dengan jenis baja yang digunakan pada saat melakukan penelitian.

Biasanya unsur paduan sengaja ditambahkan ke dalam baja dengan tujuan seperti menaikkan hardenability, memperbaiki kekuatan pada suhu biasa, memperbaiki sifat mekanik pada suhu rendah atau tinggi, dan memperbaiki ketangguhan pada tingkat kekuatan atau kekerasan tentu serta menaikkan sifat tahan aus, menaikkan sifat tahan korosi, dan menaikkan sifat kemagnetan. Pengaruh unsur-unsur paduan dalam baja adalah sebagai berikut:

\section{a. Unsur Karbon (C)}

Karbon merupakan unsur yang paling banyak selain besi $(\mathrm{Fe})$ yang terdapat pada sebuah baja, unsur ini berfungsi meningkatkan sifat mekanik baja seperti kekuatan dan kekerasan yang tinggi meskipun demikian karbon juga dapat menurunkan keuletan, ketangguhan, serta berpengaruh juga terhadap pengolahan baja selanjutnya seperti pada proses perlakuan panas, proses pengubahan bentuk dan lainnya. Kandungan karbon didalam baja berkisar antara $0,1 \%-1,7 \%$.

\section{b. Unsur Mangan (Mn)}

Mangan sangat dibutuhkan dalam proses pembuatan baja. Kandungan mangan lebih dari 0,3\%. Penambahan unsur mangan dalam baja dapat menaikkan kuat tarik tanpa mengurangi atau sedikit mengurangi regangan, sehingga baja dengan penambahan memiliki sifat kuat dan ulet .

\section{c. Unsur Silikon (Si)}

Silikon dalam baja dapat meningkatkan kekuatan, kekerasan, kekenyalan, ketahanan aus, dan ketahanan terhadap panas dan karat. Unsur silikon merupakan pembentuk karbida. Silikon cenderung membentuk partikel oksida sehingga memperbanyak pengintian Kristal dan mngurangi pertumbuhan akibatnya struktur butir semakin halus .

d. Unsur Nikel (Ni) 
Nikel mempunyai pengaruh yang sama seperti mangan, yaitu memperbaiki kekuatan tarik dan menaikkan sifat ulet, tahan panas. Pada baja terdapat unsur nikel sekitar $0.4 \%$ maka baja tahan terhadap terhadap korosi. Unsur nikel yang bertindak sebagai tahan karat (korosi) disebabkan nikel bertindak sebagai lapisan penghalang yang melindungi permukaan baja .

\section{e. Unsur Chrom $(\mathrm{Cr})$}

Chrom merupakan unsur paduan setelah karbon. Chrom dapat membentuk karbida. Chrom digunakan untuk meningkatkan kekerasan baja, kekuatan tarik, ketangguhan, ketahanan abrasi, korosi dan tahan terhadap suhu tinggi. Penambahan chrom pada baja menghasilkan struktur yang lebih halus dan membuat sifat baja dikeraskan lebih baik.

\section{f. Unsur Vanadium (V) dan Wolfram (W)}

Unsur vanadium dan wolfram membentuk karbidat yang sangat keras dan memberikan baja dengan kekerasan yang tinggi. Kekerasan dan tahan panas yang cukup tinggi pada baja sangat diperlukan pipa dengan tekanan dan temperatur tinggi.

\section{Diagram Fasa Baja karbon (Fe-C)}

Diagram fasa besi karbon ini menjadi landasan untuk laku-panas kebanyakan jenis besi dan baja yang kita kenal. Baja murni yang dipanaskan akan mengalami dua perubahan struktur mikro sebelum baja tersebut meleleh.

Karena adanya gaya tarik menarik antar atom, maka atom-atom logam mulai membentuk persenyawaan satu dengan yang lain. Persenyawaan ini akan membentuk suatu bagan geometrik tertentu hingga menjadi kristalit. Bentuk geometri pada logam besi dan baja biasanya berupa kubus yang tersusun dari atom-atom. Struktur mikro baja dapat dipahami melalui diagram besi karbon (Fe3-C).

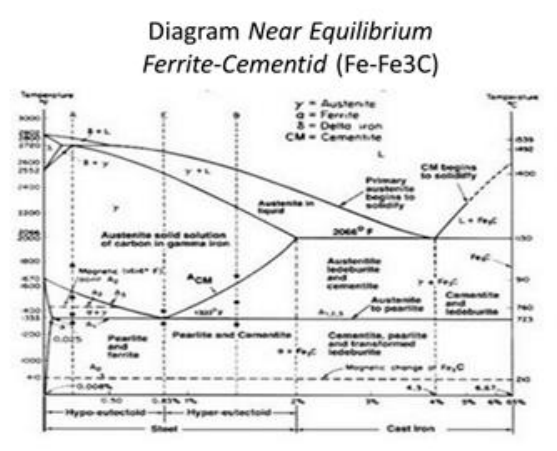

Karbon larut di dalam besi dalam bentuk larutan padat hingga $0,05 \%$ berat pada temperatur ruang. Baja dengan atom karbon terlarut hingga jumlah tersebut memiliki alpha ferrite pada temperatur ruang. Pada kadar karbon lebih dari $0.05 \%$ akan terbentuk endapan karbon dalam bentuk hard intermetallic stoichiometric compound (Fe3C) yang dikenal sebagai cementite atau carbide. Selain larutan padat alpha-ferrite yang dalam kesetimbangan dapat ditemukan pada temperatur ruang terdapat fase-fase penting lainnya, yaitu deltaferrite dan gamma-austenite. Logam Besi (Fe) bersifat polymorphism yaitu memiliki struktur kristal berbeda pada temperature berbeda. Pada Fe murni, misalnya alpha-ferrite akan berubah menjadi gamma-austenite saat dipanaskan melewati temperatur $910^{\circ} \mathrm{C}$. Pada temperature yang lebih tinggi, mendekati $1400^{\circ} \mathrm{C}$ gamma-austenite akan kembali berubah menjadi delta-ferrite. (Alpha dan Delta) Ferrite dalam hal ini memiliki struktur kristal BCC (Body Center Cubic) sedangkan (gamma) austenite memiliki struktur kristal FCC (Face Centered Cubic).

\section{Ferrite}

Ferrit adalah fase larutan padat yang memiliki struktur BCC (Body Center Cubic). Ferrite dalam keadan setimbang dapat ditemukan pada temperatur ruang, yaitu alpha-ferrite atau pada temperatur tinggi, yaitu delta-ferrite. Secara umum fase ini bersifat lunak, ulet, dan magnetic hingga temperatur tertentu. Kelarutan karbon di dalam fase ini relatif lebih kecil dibandingkan dengan kelarutan karbon di dala fase larutan padat lain di dalam baja, yaitu fase Austenite. Pada temperature ruang kelarutan karbon di dalam alpha-ferrite hanyal mengeksploitasi sifatsifat ferrite. Baja lembaran berkadar karbon rendah dengan fase tunggal ferrite misalnya, banyak di produksi untuk proses pembentukan logam lembaran.

2. Pearlite

Pearlite adalah suatu campuran lamellar dari ferrite dan cementite. Konstituen ini terbentuk dari dekomposisi Austenite melalui reaksi eutectoid pada keadaan setimbang, dimana lapisan ferrite dan cementite terbentuk secara bergantian untuk menjaga keadaan kesetimbangan komposisi eutectoid. Pearlite memiliki struktur yang lebih keras daripada ferrite, yang terutama disebabkan oleh adanya fase cementite atau carbide.

3. Austenite

Fase Austenite memiliki struktur atom FCC (Face Centered Cubic). Dalam keadaan setimbang fase Austenite ditemukan pada temperature tinggi. Fase ini bersifat non magnetic dan ulet, pada temperature tinggi. Kelarutan atom karbon di dalam larutan padat Austenite lebih besar jika dibandingkan dengan kelarutan atom karbon pada fase Ferrite. Secara geometri, dapat dihitung perbandingan besarnya ruang intertisi di dalam fase Austenite (atau kristal FCC) dan fase Ferrite (atau kristal BCC). Perbedaan ini dapat digunakan untuk menjelaskan fenomena transformasi fase pada saat pendinginan Austenite yang berlangsung secara cepat. Selain pada temperatur tinggim Austenite pada system Ferrous dapat pula direkayasa agar stabil pada temperature ruang. Elemen-elemen 
seperti Mangan dan Nickel misalnya dapat menurunkan laju transformasi dari gamma-austenite menjadi alpha-ferrite. Dalam jumlah tertentu elemen-elemen tersebut akan menyebabkan Austenite stabil pada temperatur ruang.

4. Cementite

Cementite atau carbide dalam system paduan berbasis besi adalah stoichiometric inter-metallic compound $\mathrm{Fe} 3 \mathrm{C}$ yang keras dan getas. Nama cementite berasal dari kata caementum yang berarti stone chip atau lempengan batu. Cementite sebenarnya dapat terurai menjadi bentuk yang lebih stabil yaitu Fe dan $\mathrm{C}$ sehingga sering disebut sebagai fase metastabil. Namun untuk keperluan praktis, fase ini dapat dianggap sebagai fase stabil. Cementite sangat penting perannya di dalam membentuk sifatsifat mekanik akhir baja. Cementite dapat berada di dalam system besi baja dalam berbagai bentuk seperti bentuk bola, bentuk lembaran (berselang seling dengan alpha ferrite), atau partikel-partikel carbide kecil. Bentuk, ukuran, dan distribusi karbon dapat direkayasa melalui siklus pemanasan dan pendinginan. Jarak rata-rata antar karbida dikenal sebagai lintasan Ferrite rata-rata adalah parameter penting yang dapat menjelaskan variasi sifat-sifat besi baja. Variasi sifat luluh baja diketahui berbanding lurus dengan logaritmik lintasan ferrite rata-rata.

\section{Martensite}

Martensite adalah mikro konstituen yang terbentuk tanpa melalui proses difusi. Konstituen ini terbentuk saat Austenite didinginkan secara sangat cepat, misalnya melalui proses quenching pada medium air. Transformasi berlangsung pada kecepatan sangat cepat, mendekati orde kecepatan suara, Sehingga tidak memungkinkan terjadi proses difusi karbon. Transformasi martensite diklasifikasikan sebagai proses transformasi tanpa difusi yang tidak tergantung waktu (diffusionless time-independent transformation). Martensite yang terbentuk berbentuk seperti jarum yang bersifat sangat keras dan getas. Fase martensite adalah fase metastabil yang akan membentuk fase yang lebih stabil apabila diberikan perlakuan panas. Martensite yang keras dan getas diduga terjadi karena proses transformasi secara mekanik (geser) akibat adanya atom karbon yang terperangkap pada struktur kristal pada saat terjadi transformasi polimorf dari FCC ke BCC.

\section{Teori Dasar Pipa}

Teknologi jaringan pipa berkembang sejalan dengan teknologi pertambangan. Dimana manusia dapat membangun terminal produksi, sehingga prosesnya dapat langsung berjalan dilapangan. Untuk itu dibutuhkan jaringan pipa yang dibentangkan antara sumur ke fasilitas produksi, atau dari fasilitas platform produksi yang satu ke fasilitas platform produksi lainnya.

Pertama kali sistem pemipaan yang menggunakan logam adalah di Greek, Romawi. yang terbuat dari lead dan bronze, dimana saat itu teknologi pengecoran logam mulai dikenal. Selanjutnya sistem pemipaan berkembang dengan material logam yang bervariasi seiring dengan perkembangan dan kebutuhan masyarakat, yang akhirnya saat ini berbagai logam hingga non logam berkembang pesat dalam dunia industri termasuk juga sistem pemipaannya. Pada teori dasar pipa akan di jelaskan tentang jenis-jenis pipa terutama dari proses pembuatan pipa, bahan-bahan yang digunakan untuk pembuatan pipa, ketebalan dinding pipa, dan kode material yang digunakan

\section{Jenis Pipa}

Dari sekian jenis pembuatan pipa secara umum dapat dikelompokan menjadi dua bagian yaitu:

a. Seamless pipe

Adalah jenis pipa yang dibuat dari besi bulat yang dibentuk sedemikian rupa menjadi bentuk pipa. Pipa jenis ini memiliki dimensi diameter luar 1/8 inchi sampai 26 inchi.

\section{b. Electric Resistance Welded (ERW)}

Adalah pipa yang dibentuk dari plat datar kemudian dihubungkan dengan pengelasan butt weld dengan induksi frekuensi tinggi.

\section{Kode Material Pipa}

Standar kode material pipa yang sering digunakan pada proses produksi minyak dan gas alam adalah standar ASTM (American Standar Testing and Material), API (American Petroleum Institute), dan ANSI (American National Standard Institute). Kode material pipa hanya sebuah penamaan untuk membedakan pipa dari proses manufakturnya, kode material pipa yang digunakan untuk pengujian adalah ASTM A106 grade A Seamless dan ASTM A53 grade B ERW. Dari kedua kode tersebut hanya dibedakan berdasarkan grade dan proses manufakturnya, ASTM A106 terbagi dalam 3 grade tergantung tensile strenghnya, untuk grade A (48 ksi), grade B (60 ksi) dan grade C (70 ksi). ASTM A53 material pipa yang biasanya dilapisi oleh Zinc (galvanize) yang biasanya merupakan alternatif dari ASTM A106 ini juga terbagi dalam 3 grade yaitu grade $A, B$, dan $C$ yang memiliki tensile strength yang sama dengan grade A, B, dan C ASTM A106. Untuk grade A diambil dari ASTM A106 maka dapat dilihat chemical requirementnya seperti yang ditunjukkan pada gambar 2. Chemical Requirements. 
TABLE 1 Chemical Requirements

\begin{tabular}{|c|c|c|c|}
\hline & \multicolumn{3}{|c|}{ Composition, \% } \\
\hline & Grade A & Grade B & \\
\hline Carbon, $\max ^{A}$ & 0.25 & 0.30 & \\
\hline Manganese & $0.27-0.93$ & $0.29-1.06$ & 1 \\
\hline Phosphorus, max & 0.035 & 0.035 & \\
\hline Sulfur, max & 0.035 & 0.035 & \\
\hline Silicon, $\min$ & 0.10 & 0.10 & \\
\hline Chrome, $\max ^{B}$ & 0.40 & 0.40 & \\
\hline Copper, $\max ^{B}$ & 0.40 & 0.40 & \\
\hline Molybdenum, $\max ^{B}$ & 0.15 & 0.15 & \\
\hline Nickel, $\max ^{B}$ & 0.40 & 0.40 & \\
\hline Vanadium, $\max ^{B}$ & 0.08 & 0.08 & \\
\hline
\end{tabular}

Gambar 2. Chemical Requirements grade A A106

Untuk grade B diambil dari API 5L A53 maka dapat dilihat chemical requirementnya seperti yang ditunjukkan pada gambar 3. Chemical requirements

\begin{tabular}{|c|c|c|c|c|c|c|c|c|c|}
\hline \multicolumn{10}{|c|}{ TABLE 1 Chemical Requirements } \\
\hline & Cadon & Menganesese & Phosphons & Sultion & Copoper & Nivelth & Chominint & Thyodononint & Venasoumat \\
\hline \multicolumn{10}{|c|}{ Type S (seamless pipe) } \\
\hline Gaded A & 0.25 & 0.56 & 0.05 & 0.045 & 0.40 & 0.40 & 0.40 & 0.15 & 0.08 \\
\hline Gade B & 0.30 & 1.20 & 0.05 & 0.045 & 0.40 & 0.40 & 0.40 & 0.15 & 0.08 \\
\hline \multicolumn{10}{|c|}{ 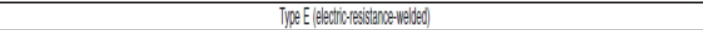 } \\
\hline GadeA $A$ & 0.25 & 0.05 & 0.65 & 0.045 & 0.50 & 0.40 & 0.40 & 0.15 & 0.08 \\
\hline Gade B & 0.30 & 1.20 & 0.05 & 0.045 & 0.50 & 0.40 & 0.40 & 0.15 & 0.08 \\
\hline \multicolumn{10}{|c|}{ 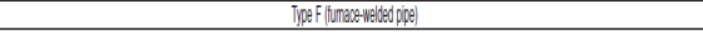 } \\
\hline GadeA & 0.30 & 1.20 & 0.05 & 0.045 & 0.40 & 0.40 & 0.40 & 0.15 & 0.08 \\
\hline
\end{tabular}

${ }^{4}$ The tobal composition ior these five elementis stal not exroed $1.00 \%$

\section{Gambar 3. Chemical Requirements grade B A53}

Jika dikategorikan berdasarkan unsur paduan karbon (C) maka grade $\mathrm{A}$ adalah kategori baja karbon rendah dan grade B kategori baja karbon sedang.

\section{Sifat Mekanik}

Sifat mekanik baja karbon sangat diperlukan untuk mengetahui apakah bahan sudah sesuai dengan standard yang dizinkan. Sifat mekanik meliputi tentang komposisi kimia, kekuatan tarik, kekerasan material, struktur mikro.

Dalam penelitian ini dilakukan beberapa tahap pengujian terhadap test-sample yang nantinya dari hasil pengujian akan dianalisis. Adapun tahap pengujian yang akan dilakukan yaitu :

\section{Komposisi kimia (chemical composision)}

Baja pada dasarnya memiliki kandungan unsur dengan presentase yang berbeda-beda didalamnya. Kompoisi kima merupakan suatu uji yang bertujuan untuk mengetahui kandungan unsur kimia yang terdapat pada logam atau baja dari suatu benda uji. Biasanya pengujian komposisi kimia dilakukan pada saat dimulai suatu penelitian yang dimaksudkan agar sebelum melakukan suatu penelitian, sudah terlebih dahulu mengetahui klasifikasi dari baja atau spesimen yang akan digunakan. Pengujian komposisi kimia dilakukan dengan menggunakan mesin uji Optical Emision Spectroscopy (OES).

\section{Optical Emision Spectroscopy (OES)}

Alat uji komposisi kimia yaitu Optical Emision Spectroscopy (OES) yaitu pengujian sinar radioaktif dan gas argon ditembakkan terhadap sampel, lalu kemudian dari hasil penembakan didapatkan print out hasil uji yang terbaca pada layar komputer. Analisis komposisi kimia ini dapat digunakan untuk mengetahui kadar karbon baja, apakah baja tersebut masuk dalam jenis baja karbon rendah (low carbon steel), baja karbon sedang (medium carbon steel), dan baja karbon tinggi (high carbon steel) atau malah masuk kedalam kategori baja paduan.

\section{Kekuatan Tarik}

Kekuatan tarik adalah suatu metode yang digunakan untuk menguji kekuatan suatu bahan atau material dengan cara memberikan beban gaya yang sesumbu. Hasil yang didapatkan dari pengujian tarik sangat penting untuk rekayasa teknik dan desain produk karena menghasilkan data kekuatan material. Pengujian tarik digunakan untuk mengukur ketahanan suatu material terhadap gaya statis yang diberikan secara lambat.

Pengujian tarik adalah dasar dari pengujian mekanik yang dipergunakan pada material. Dimana specimen uji yang telah distandarisasi, dilakukan pembebanan uniaxial sehingga specimen uji mengalami peregangan dan bertambah panjang hingga akhirnya patah. Pengujian tarik relatif sederhana, murah dan sangat terstandarisasi disbanding pengujian lain. Hal-hal yang perlu diperhatikan agar pengujian menghasilkan nilai yang valid adalah; bentuk dan dimensi spesimen uji, pemilihan grips dan lain-lain.

a. Bentuk dan Dimensi Spesimen uji

Spesimen uji harus memenuhi standard dan spesifikasi dari ASTM, JIS. Bentuk dari spesimen sangat penting untuk menghindari terjadinya patah atau retak pada daerah grip atau yang lainnya. Standarisasi dari bentuk specimen uji yang dimaksudkan agar retak dan patahan terjadi di daerah gauge length.

\section{b. Grip and Face Selection}

Face dan grip adalah faktor penting. Dengan pemilihan setting yang tidak tepat, specimen uji akan terjadi slip atau bahkan pecah dalam daerah grip (jaw-break). yang akan menghasilkan hasil yang tidak valid. Face harus selalu tertutup di seluruh permukaan yang kontak dengan grip agar specimen uji tidak bergesekan langsung dengan face. Beban yang diberikan pada bahan uji ditransmisikan pada pegangan bahan yang di uji. Dimensi dan ukuran pada benda uji di sesuaikan dengan standar yang digunakan berdasarkan JIS Z 2201 yang di tunjukan pada gambar 4 . 


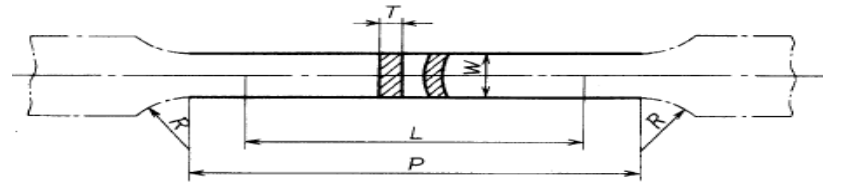

tarik

Bila gaya tarik terus diberikan kepada suatu bahan (logam) sampai putus, maka akan didapatkan profil tarikan yang lengkap berupa kurva seperti digambarkan pada gambar 5 , kurva ini menunjukkan hubungan antara gaya tarikan dengan perubhan panjang. Profil ini sangat diperlukan dalam desain yang memakai bahan tersebut dan dapat dilihat pada gambar 5 .

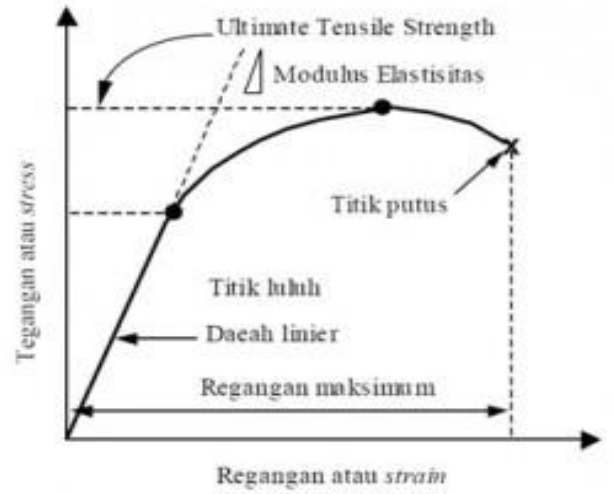

Gambar 5. Kurva Tegangan-Regangan

Pada prakteknya nilai hasil pengukuran tegangan pada suatu pengujian tarik dan tekan pada umumnya merupakan nilai teknik. Regangan akibat beban tarik yang terjadi, panjang akan menjadi berkurang dan diameter pada spesimen akan menjadi besar yang menyebabkan terjadinya deformasi plastis.

Biasanya yang menjadi fokus perhatian adalah kemampuan maksimum bahan tersebut dalam menahan beban. Kemampuan ini umumnya disebut "Ultimate Tensile Strength" dalam bahasa Indonesia disebut tegangan tarik maksimum. Perubahan panjang dalam kurva disebut sebagai regangan teknik, yang didefinisikan sebagai perubahan panjang yang terjadi akibat perubahan statik terhadap panjang batang mula-mula.

Kekuatan tarik biasanya ditentukan dari suatu hasil pengujian tarik adalah kuat luluh (Yield Strength) dan kuat tarik (Ultimate Tensile Strength). Kekuatan tarik atau kekuatan tarik maksumum (Ultimate Tensile Strength / UTS), adalah beban maksimum dibagi luas penampang lintang awal benda uji.

$$
S_{u}=\frac{P_{\text {maks }}}{A_{0}}
$$

$$
\text { Dimana, } \begin{aligned}
S_{\mathrm{u}} & =\text { Kuat tarik }\left(\mathrm{kg} / \mathrm{mm}^{2}\right) \\
P_{\text {maks }} & =\text { Beban maksimum }(\mathrm{kg})
\end{aligned}
$$

$$
A_{0} \quad=\text { Luas Area }\left(\mathrm{mm}^{2}\right)
$$

Kekerasan Rockwell (Hardness Rockwell)

Uji kekerasan Rockwell adalah salah satu metode uji kekerasan yang didasarkan kepada sebuah identor dengan suatu gaya tekan tertentu kepermukaan yang rata dan bersih dari suatu logam yang diuji kekerasannya. Setelah gaya tekan dikembalikan ke gaya minor maka yang dijadikan dasar perhitungan nilai kekerasan Rockwell bukanlah hasil pengukuran diameter ataupun diagonal bekas lekukan tetapi justru dalamnya bekas lekukan yang terjadi. Inilah kelainan cara Rockwell dibandingkan dengan cara pengujian kekerasan lainnya.

Pengujian Rockwell yang umumnya dipakai yaitu $\mathrm{HR}_{\mathrm{A}}, \mathrm{HR}_{\mathrm{B}}, \mathrm{HR}_{\mathrm{C}}$. $\mathrm{HR}$ itu sendiri merupakan suatu singkatan dari kekerasan Rockwell atau Rockwell hardness number dan kadang-kadang disingkat dengan huruf R saja. Pengujian kekerasan dengan metode Rockwell ini berdasarkan standard ASTM E 18. Tingkat skala kekerasan menurut metode Rockwell adalah berdasarkan pada jenis indentor yang digunakan pada masing-masing skala.

Dalam metode Rockwell ini terdapat dua macam indentor yang ukurannya bervariasi, kedua jenis indentor itu adalah:

a. Kerucut intan dengan besar sudut $120^{\circ}$, dikenal pula dengan "Rockwell cone".

b. Bola baja dengan berbagai ukuran, dikenal pula dengan "Rockwell".

Untuk cara pemakaian skala ini, lebih dahulu ditentukan dan dipilih ketentuan angka kekerasan maksimum yang boleh digunakan oleh skala tertentu. Jika pada skala tertentu tidak tercapai angka kekerasan yang akurat, maka kita tentukan skala lain yang dapat menunjukan angka kekerasan yang jelas. Sebagaimana rumus tertentu, maka skala memiliki standar atau acuan.

Untuk mendapatkan nilai $\mathrm{HR}_{\mathrm{B}}$ harus menggunakan sebuah indentor berupa bola baja dengan ukuran $\varnothing$ $1 / 16$ " dan ini digunakan untuk jenis logam yang tidak mendapatkan perlakuan pengerasan sebelumnya (sepuh) dan untuk semua jenis nonferrous dalam kondisi padat.

\section{Struktur Mikro}

Pengujian struktur ini bertujuan untuk mempelajari dan mengetahui karakteristik struktur mikro logam, yang meliputi bentuk besar butiran, arah struktur dan distribusi berbagai tahapan dan inklusi yang memiliki efekbesar pada sifat mekanik logam. Dengan pengujian metallografi dapat mengetahui perlakuan mekanik dan termal yang terjadi pada logam, dan dapat dibuat untuk memprediksi perilaku dan kondisi pada logam.

Dalam metode pengujian metallografi memerlukan persiapan yang cukup teliti dan cermat, agar memperoleh hasil struktur mikro yang baik. 
Oleh karena itu diperlukan beberapa tahap dalam persiapan yaitu :

1. Pemotongan Benda Uji

Untuk dapat memudahkan dalam penelitian, maka benda uji dipotong sesuai dengan ukuran alat uji metallografi dala arah vertical dan horizontal.

\section{Mounting}

Setelah dipotongkemudian benda uji di mounting, yang bertujuan agar memudahkan pengoperasian selama preparasi (grinding dan polishing).

\section{Grinding}

Setelah benda uji di mounting baru kemudian diamplas secara berurutan dari yang kasar sampai yang halus memakai kekerasan kertas amplas dengan nomor : 240, 320, 400, 600, 800, 1000, 1200 dan 1500. Kertas amplas terbuat dari bahan aluminium oxide water proof. Dalam proses grinding harus selalu dialiri air bersih secara terys menerus dengan tujuan menghindari timbulnya panas dipermukaan benda uji yang kontak secara langsung dengan kertas amplas dan juga untuk menghilangkan partikel-partikel bahan abrasive yang menempel pada permukaan benda uji.

\section{Polishing}

Dalam memoles digunakan kain poles beludru dan mesin poles. Kain beludru ditempelkan pada piringan yang berputar pada mesin poles, kemudian kain diberi pasta alumina berupa partikel abrasive yang sangat halus. Selama pemolesan benda uji digerakkan kedepan, kebelakang dan berputar dengan tujuan agar partikel-partikel abrasive dapat terdistribusi dengan merata diatas piringan pemoles. Setiap satu langkah pemolesan berakhir, benda uji harus selalu dicuci dan dibersihkan, yaitu dengan menggunakan alcohol lalu dikeringkan dengan udara hangat (hair dryer). Benda uji yang sudah dipoles kemudian diperiksa dibawa mikroskop untuk dilihat apakah masih ada goresan-goresan, inklusi non logam, retakan dan lain-lain. Apabila masih terdapat goresan, retakan dan lain-lain maka benda uji harus dipoles kembali. Polishing akan berakhir bila sudah diperoleh permukaan benda uji yang bebas dari goresan, retakan dan permukaannya seperti cermin. 5. Etsa

Setelah benda uji selesai dalam proses polishing, maka selanjutnya dilakukan pengetsaan. Dimana permukaan benda uji dicelup dengan waktu \pm 5 detik menggunakan larutan Nital 2\% (alkohol $97 \% 100 \mathrm{ml}+\mathrm{HNO}_{3} 3 \mathrm{ml}$ ) setelah itu dibersihkan dengan air dan alkohol $97 \%$ kemudian dikeringkan dengan udara hangat (hair dryer), tujuannya agar terhindar dari oksidasi udara sekitar.

\section{Pengujian Struktur Mikro}

Amati permukaan specimen yang telah di etsa dengan mikroskop optik pada perbesaran 100x, 200x, dan 500x. Pada pengujian ini, akan didapat perbedaan struktur mikro dari masing-masing benda uji.

\section{Proses Produksi Gas Alam (Liquified Natural Gas)}

Proses produksi gas alam adalah suatu proses gas alam yang dicairkan menjadi liquid gas alam, dimana proses tersebut memiliki 5 proses utama dalam pencairan gas alam yang biasa disebut plant.

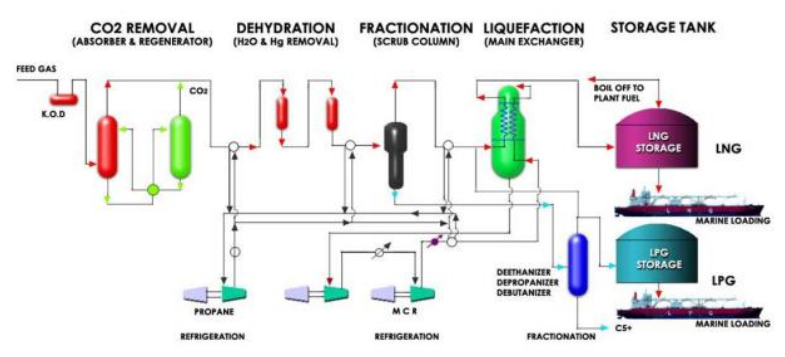

Proses pertama pada tahap pencairan gas alam adalah menghilangkan karbon dioksida yang ada di gas ala,. Karbon dioksida ini harus di hilangkan dari gas alam karena $\mathrm{CO}_{2}$ bisa membeku dalam proses pada temperature rendah yang akan menyumbat pipa. $\mathrm{CO}_{2}$ tidak memiliki nilai pembakaran, seperti yang kita tau bahwa $\mathrm{CO}_{2}$ merupakan emisi hasil pembakaran. Setelah melalui tahap pertama, tahap berikutnya yaitu menghilangkan air dan merkuri yang terdapat pada gas alam. Alasan menghilangkan air dan merkuri dari gas alam karena air bisa membeku jika temperatur $0{ }^{\circ} \mathrm{C}$ (1 atm) sedangkan LNG membutuhkan temperatur dibawah $-150^{\circ} \mathrm{C}$, jika terdapat air pada gas alam dapat mengakibatkan penyumbatan terhadap pipa. Air yang terdapat pada gas alam dihilangkan menggunakan alat mirip silica gel yang disebut molecular sieve. Setelah menghilangkan air tahap berikutnya adalah menghilangkan merkuri yang terdapat pada gas alam, merkuri adalah zat yang dapat merusak pipa yang terbuat dari bahan aluminium karena pada tahap terakhir terdapat pipa yang terbuat dari baha aluminium alloy aka dari itu jika merkuri tidak dihilangkan dapat merusak pipa pada tahap akhir proses produksi. Cara untuk memisahkan merkuri dengan gas alam yaitu menggunakan SIAC (sulphur impregnated active carbon).

Pada tahap yang ke tiga gas alam dipecahpecah sesuai komponen penyusunnya (Metana, Etana, Propana, Butana, dan Pentana+). Proses ini menggunakan 4 menara distilasi yang proses pemisahannya berdasarkan titik didih. Menara distilasi yang pertama adalah scrub column atau demethanizer yang bertugas memisahkan metana dari hidrokarbon lainnya. Kedua adalah deethanizer yang bertugas memisahkan etana dari hidrokarbon lainnya, ketiga adalah depropanizer yang bertugas memisahkan propane dari hidrokarbon lainnya, yang terakhir adalah debutanizer yakni yang bertugas memisahkan butane dari pentana+. Setelah melalui 4 
menara, masing-masing komponen menuju prosesnya masing-masing. Metana menuju MHE (Main Heat Exchanger) di plant 5 untuk didinginkan dan dicairkan menjadi LNG, Etana dan sebagian propane menuju plant 4 sebagai pendingin gas alam yang akan di cairkan, lalu propane dan butane menuju proses yang lain untuk dijadikan LPG sementara pentana+ dijadikan kondensat yang akan di kirim kembali ke sumur di upstream untuk di proses menjadi bensin atau bahan bakar hidrokarbon berat lainnya.

Pada tahap keempat yaitu siklus refrigerant prophana yang mendinginkan MCR dan kemudian mendinginkan gas alam pada plant 5 yang berfungsi untuk myirkulasikan pendingin yang terdiri dari (N2, metana, etana, dan propana). Dan pada tahap terakhir disinilah gas alam yang sebagian besar terdiri dari metana akan didinginkan menggunakan MCR (Multi Component Refrigerant) dan di cairkan dengan MHE (Main Heat Exchanger). Setelah melewati proses ini LNG akan disimpan distorage tank dan siap untuk dipasarkan, metode pencairan yang digunakan adalah metode APCI yang termasuk teknologi pencairan gas alam yang banyak digunakan.

\section{METODOLOGI DAN HASIL PENELITIAN Diagram Alir}

Metode penelitian ini dilakukan sesuai langkah-langkah diagram alir (flow chart) sebagai berikut :

\section{Benda Uji}

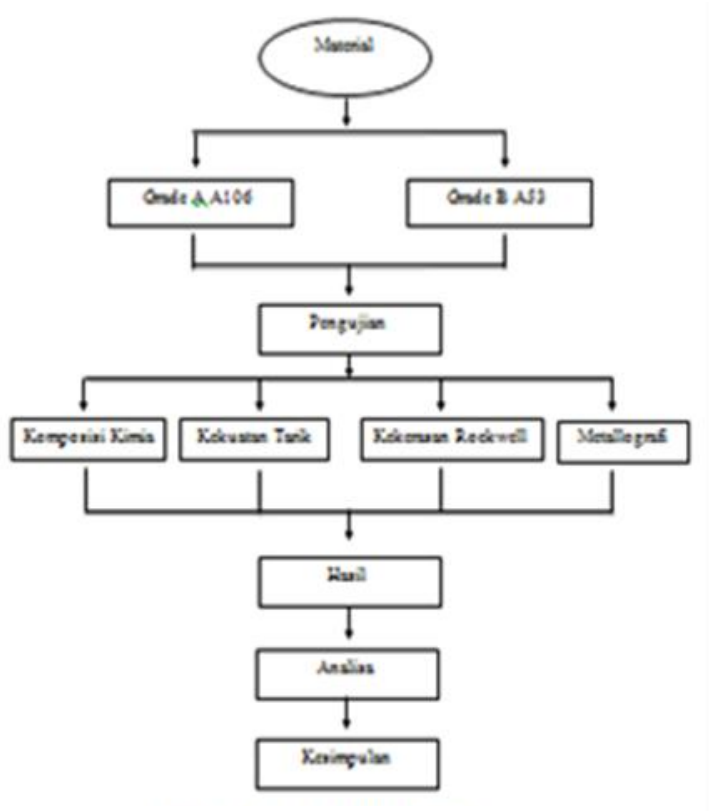

Material yang di gunakan untuk proses pengujian terdiri dari 2 macam, yaitu pipa carbon steel grade A A106 dan carbon steel grade B A53 dengan bentuk silinder yang mempunyai dimensi : diameter dalam $=107 \mathrm{~mm}$, diameter luar $=110,4$ $\mathrm{mm}$, dan tebal $8 \mathrm{~mm}$ seperti terlihat pada gambar 3.2. Benda Uji Grade A A106 dan Grade B A53.

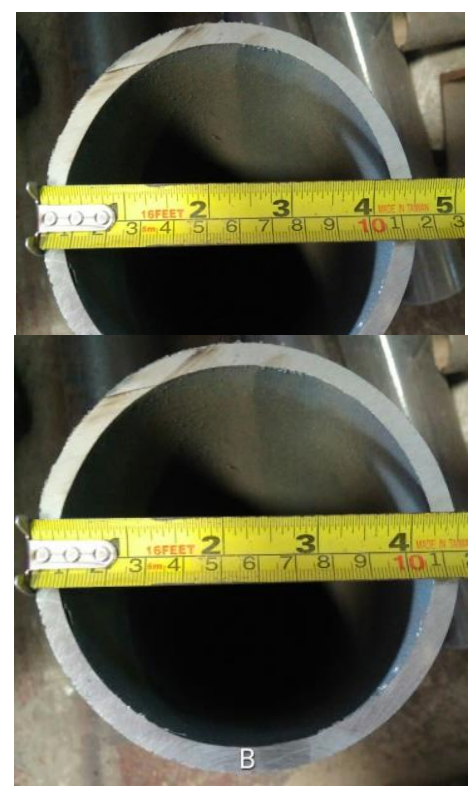

Gambar 8. Benda Uji Grade A A106 dan Grade B A53.

\section{HASIL PENELITIAN DAN PEMBAHASAN \\ Data Hasil Penelitian}

Spesimen bahan yang diambil dari potongan pipa baja karbon grade A A106 dan baja karbon grade B A53 digunakan untuk pengujian komposisi kimia, pengujian kekuatan tarik, pengujian metallografi dan pengujian kekerasan Rockwell. Data pengujian diambil dari laboratorium uji departemen metalurgi dan material Universitas Indonesia dengan menggunakan mesin uji komposisi kimia, mesi uji kekuatan tarik, mesin uji metallografi dan mesin uji kekerasan Rockwell. Hasil yang didapat dari pengujian adalah nilai yang muncul dari hasil tes pengujian.

\section{Pembahasan Pengujian Komposisi Kimia}

Dari hasil pengujian komposisi kimia yang didapatkan kemudian kedua grade dibandingkan, perbandingan komposisi kimia grade A A106 dan grade B A53 sebagai berikut:

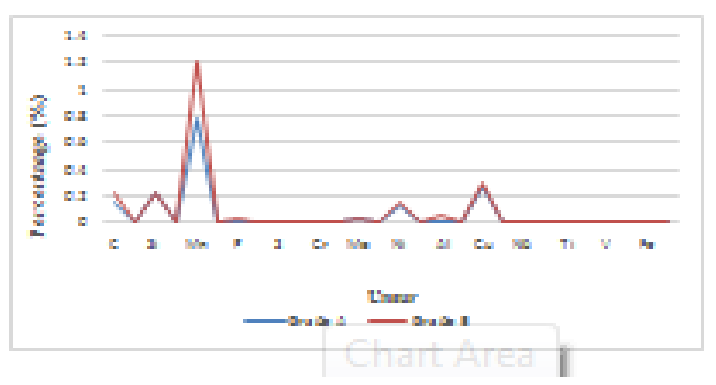

Gambar 9. Grafik Perbandingan Hasil Uji Komposisi Kimia Grade A dan Grade B. 
Setelah dilakukan uji komposisi kimia pada kedua benda uji baja karbon grade A A106 dan baja karbon grade B A53, diketahui kedua benda uji termasuk dalam golongan baja karbon rendah. Dengan kadar karbon < $0.25 \%$ C yaitu $0.159 \% \mathrm{C}$ untuk baja karbon grade A dan $0.076 \% \mathrm{C}$ baja karbon grade B dengan unsur paduan utamanya adalah mangan. Kadar karbon yang kurang dari $0.25 \%$ pada hasil uji berada dibawah nilai maksimum yang ditentukan ASTM A106 dan ASTM A53.

Sedangkan kadar mangan grade A $0.773 \%$ dan grade B $0.424 \%$ pada hasil uji. kadar mangan pada hasil uji masih dibawah nilai maksimum ASTM A106 dan ASTM A53, mangan tidak memberikan pengaruh yang sungguh-sungguh pada struktur, mangan dapat mencegah penggrafitan dan menstabilkan sementit.

\section{Pembahasan Pengujian Kekuatan Tarik}

Dalam penelitian ini, pengujian tarik dilakukan untuk mengetahui kekuatan tarik dari spesimen uji.

Tabel 1. Hasil Uji Tarik Grade A

\begin{tabular}{|c|c|c|c|c|c|c|c|c|}
\hline No. & $\begin{array}{l}\text { Bende } \\
\text { UF }\end{array}$ & Syaime & $\begin{array}{l}\text { Dimenxi } \\
\text { Lkur } \\
(\mathrm{men})\end{array}$ & $\begin{array}{c}\text { Lus } \\
\text { Ames } \\
\left(\mathrm{man}^{2}\right)\end{array}$ & $\begin{array}{l}\text { Panjeng } \\
\text { Thur } \\
\text { (man) }\end{array}$ & 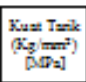 & 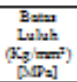 & 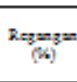 \\
\hline : & \multirow{4}{*}{ Gade } & (At) & $\frac{T-5.40}{W-12.50}$ & 67.50 & 50 & $56[549]$ & 4! [402] & 28.32 \\
\hline 2 & & (AD) & \begin{tabular}{|l|}
$T-5.30$ \\
$W-12.55$
\end{tabular} & 66.52 & 50 & $56[349]$ & $43[42:]$ & 26.04 \\
\hline 3 & & (A) & \begin{tabular}{|l|}
$T-5.45$ \\
$W-12.40$
\end{tabular} & 67.58 & 50 & $56[540]$ & $44[43:]$ & 26.60 \\
\hline 4 & & (A4) & \begin{tabular}{|c|}
$T-5.62$ \\
$W-12.40$ \\
\end{tabular} & 60.68 & 50 & $56[540]$ & $4 ![402]$ & 25.50 \\
\hline
\end{tabular}

Tabel 2. Hasil Uji Tarik Grade B

\begin{tabular}{|c|c|c|c|c|c|c|c|c|}
\hline No. & $\begin{array}{c}\text { Bend } \\
\text { LF }\end{array}$ & Sgaime & $\begin{array}{c}\text { Dimensi } \\
\text { Ukur } \\
\text { (min) }\end{array}$ & $\begin{array}{l}\text { Las } \\
\text { Amas } \\
\left(\mathrm{mm}^{2}\right)\end{array}$ & 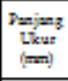 & 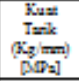 & 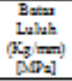 & $\begin{array}{c}\operatorname{Reg}=z= \\
(\mu)\end{array}$ \\
\hline : & \multirow{4}{*}{ Gade } & (B:) & \begin{tabular}{|c|}
-5.40 \\
$W-12.50$
\end{tabular} & 64.84 & 50 & 37 [36) & $3:[304]$ & 41.60 \\
\hline 2 & & (B2) & \begin{tabular}{|l}
$T-5.30$ \\
$W-12.55$
\end{tabular} & 65.10 & 50 & 37 [363] & $29[284]$ & 41.60 \\
\hline 3 & & (B) & 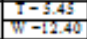 & $66.6 \mathrm{t}$ & 50 & 36 [353] & 30 [204] & 35.03 \\
\hline 4 & & (B4) & 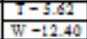 & 65.45 & 50 & 36 [353] & $29[284]$ & 39.86 \\
\hline
\end{tabular}

Dalam pengujian tarik dibagi menjadi 2 (dua) sampel yaitu sampel 1 (baja karbon grade A), sampel 2 (baja karbon grade B) yang masing-masing jenis sampel dibagi menjadi 4 spesimen dengan dimensi ukur yang berbeda.

Dari table 1 dan tabel 2, kekuatan tarik baja karbon grade A berbeda jauh dengan kekuatan tarik baja karbon grade B. Karena baja karbon grade A mempunyai kadar Molybdenum (Mo) 0.29\% lebih besar dibandingkan dengan grade $B$ yang mempunyai kadar $0.005 \%$ Mo, unsur ini dapat meningkatkan kekuatan baja tanpa kehilangan keuletan. Hal ini dibuktikan bahwa regangan baja karbon grade B lebih tinggi daripada baja karbon grade A. Unsur Ni menaikkan ketangguhan atau ketahanan terhadap beban bentur sedangkan kadar Si menaikkan ketahanan oksidasi

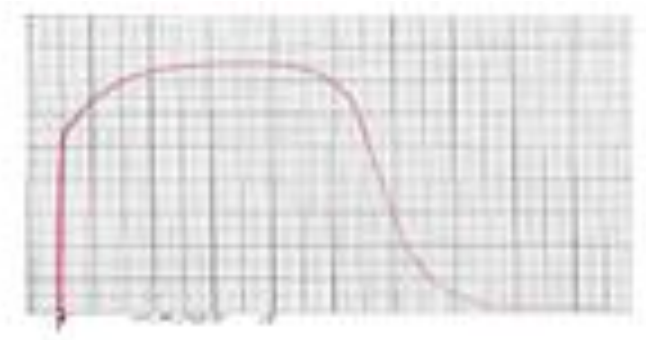

Gambar 10. Kurva Baja Karbon Grade A no.1.

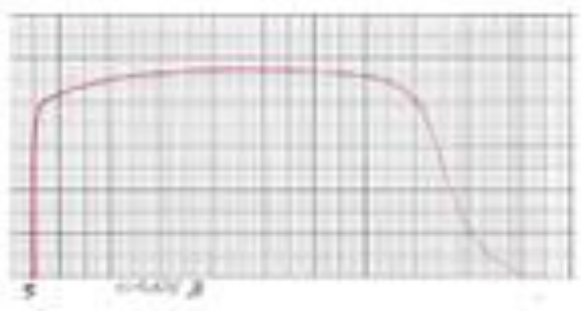

Gambar 11. Kurva Baja Karbon Grade B no.1.

\section{Pembahasan Pengujian Struktur Mikro}

Pengujian struktur mikro pada baja karbon grade A A106 dan baja karbon grade B A53. Pada baja karbon grade A A106 dan grade B A53 akan terlihat grafit lamellar tipe A, tipe ini hasil dari struktur eutektik yang terurai sempurna.

Ukuran individu serpih grafit ditentukan oleh ukuran kristal austenite sekitar yang terbentuk. Pada baja karbon grade A dan baja karbon grade B akan terlihat struktur perlitik, dimana struktur perlitik terdiri dari perlit dan grafit. Perlit merupakan campuran khusus terdiri dari dua fasa dan terbentuk sewaktu austenite dengan komposisi eutectoid bertransformasi menjadi kristal ferrit dan kristal sementit, dimana struktur perlit terdiri dari pelatpelat/lamel ferrit dan sementit yang tersusun berdampingan.

Hasil pengujian struktur mikro pada baja karbon grade A A106 tidak jauh berbeda dengan baja karbon grade B A53. Akan terlihat grafit lamellar tipe A, dimana tipe ini hasil dari struktur eutektik yang terurai sempurna.

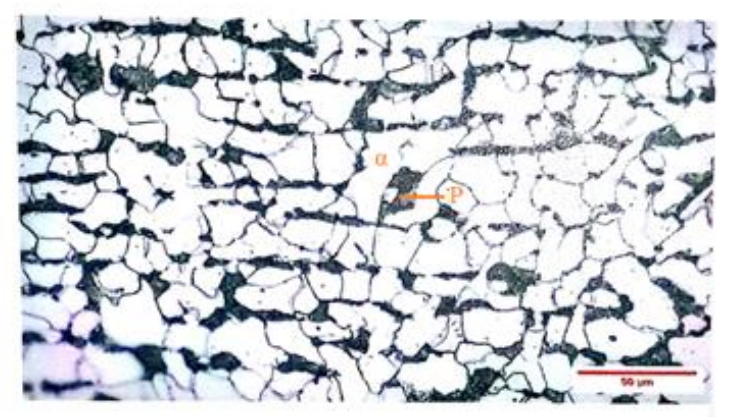




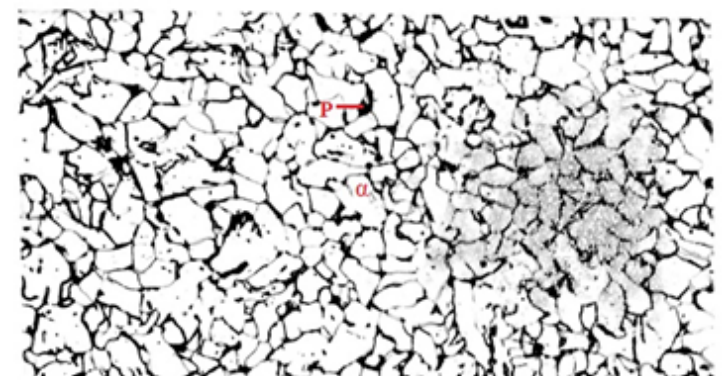

Gambar 13. Strukutr Mikro Baja Karbon grade B 53, Etsa $5 \%$

Pen

Gambar 4. 5. Struktur Mikro Baja Karbon grade B A53

$$
\text { Etsa: } 5 \%
$$

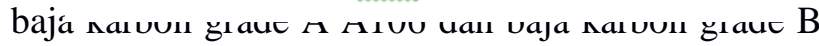
A53 akan menghasilkan perbandingan harga kekerasan, baik pada baja karbon grade A A106 maupun baja karbon grade B A53. Nilai rata-rata kekerasan dapat dilihat pada gambar 14.

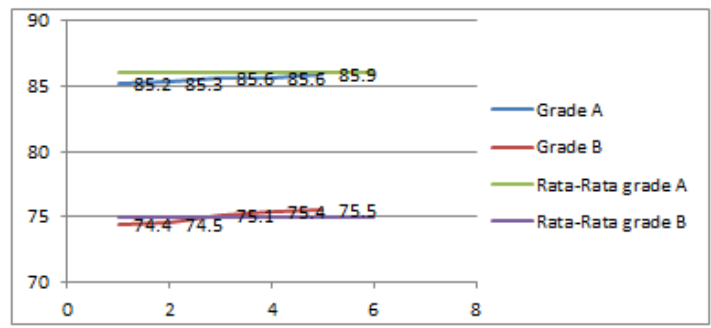

! Gambar 14. Grafik rata-rata Kekerasan Rockwell

Dari grafik diatas terlihat grade A mempunyai nilai kekerasan $85.9 \mathrm{kgf}$, berbeda dengan grade B yang mempunyai nilai kekerasan lebih rendah 75.5 kgf. Hal ini dikarenakan unsur pemadu $\mathrm{Cr}(0.10 \%)$ pada grade A lebih banyak bila dibandingkan dengan grade $\mathrm{B} \mathrm{Cr}(0.006 \%)$. Penambahan unsur krom mampu meningkatkan stabilitas pearlite dan akan meningkatkan kekuatan matrik. Selain itu, dapat meningkatkan kekuatan pada suhu tinggi dan sifat-sifat creep.

\section{SIMPULAN}

Dari hasil penelitian, pengujian spesimen dan pembahasan data maka dapat ditarik suatu kesimpulan, yaitu:

1. Hasil komposisi kimia unsur-unsur pemadu utama pada baja karbon grade A: $0.159 \% \mathrm{C}$, $0.231 \% \mathrm{Si}, 0.773 \% \mathrm{Mn}, 0.140 \mathrm{Ni}, 0.275 \mathrm{Cu}$, dan pada grade B: $0.076 \% \mathrm{C}, 0.005 \% \mathrm{Si}, 0.424 \% \mathrm{Mn}$, $0.005 \% \mathrm{Ni}, 0.025 \% \mathrm{Cu}$. Unsur Ni dan Si pada baja karbon grade A dapat meningkatkan ketahanan oksidasi dan stabilitas pearlite. Sedangkan pada baja karbon grade B unsur Ni dan Si dapat meningkatkan ketahanan oksidasi dan stabilitas pearlite.

2. Hasil Uji struktur mikro pada kedua material baja karbon memiliki struktur yang sama yaitu pearlitik. Akan tetapi, ada perbedaan pada jenis tipe lamel grafit. Pada baja karbon grade A grafit lamellar tipe A, sedangkan pada baja karbon grade B grafit lamellar tipe B.

3. Hasil pengujian sifat mekanik pada kedua jenis baja karbon mempunyai nilai kekerasan 85.9 $\mathrm{kg} / \mathrm{mm}^{2}$ (baja karbon grade A) dan $75.5 \mathrm{~kg} / \mathrm{mm}^{2}$ (baja karbon grade B. Tidak ada perbandingan yang signifikan pada kedua baja karbon tersebut, sehingga dapat dikatakan bahwa terjadinya kerusakan pada baja karbon grade B tidak terlihat dari aspek metalurgi.

4. Dari Hasil pengujian kekuatan tarik yang telah dilakukan, maka didapatkan beberapa kesimpulan. Pada uji coba ini kita meguji ketahanan bahan materialnya sejauh mana pertambahan panjangnya dan bagaimana bahan tersebut bereaksi terhadap tarikan, berdasarkan hasil percobaan dan dari grafik kurva uji tarik, baja karbon grade A mengalami perpanjangan lebih kecil dari baja karbon grade B, dikarenakan luas penampang baja karbon grade B lebih kecil dibanding baja karbon grade A. Jenis material yang berbeda, dengan perlakuan yang didapatkannya berbeda dan komposisinya yang berbeda akan menyebabkan nilai kekuatannya berbeda pula dan kurva hasil uji tariknya juga berbeda. Faktor penyebab terjadinya nilai diantara dua spesimen uji tersebut adalah dimensi yang berbeda.

5. Jadi perbandingan sifat mekanik yang dihasilkan setelah proses pengujian pada masing-masing baja karbon adalah kekerasan dan kekuatan tarik pada baja karbon grade A lebih baik bila dibandingkan dengan baja karbon grade B.

\section{KESIMPULAN}

Dari hasil pengamatan dan Analisis yang dilakukan pada tanggal 20 Januari 2017 mengenai Performansi Economizer pada proses degreasing yang digunakan pada sistem pemanasan ulang (reheater) di PT. X Plant Karawang, didapatkan beberapa kesimpulan sebagai berikut :

Aliran air pada saat pengujian aktual sama dengan aliran air pada saat desainnya yaitu merupakan aliran turbulen.

Nilai Bilangan reynold pada pengujian menjadi lebih rendah dari desainnnya hal ini disebabkan oleh adanya gradient Suhu $(\Delta \mathrm{T})$. Gradien suhu akan mempengaruhi nilai massa jenis fluida dan viskositas fluida.

Nilai koefisien perpindahan keseluruhan pada saat pengujian dari Economizer proses degreasing di PT. X Plant Karawang mengalami penurunan 
secara signifikan yaitu presentase penurunan sebesar $32 \%$.

Efektivitas aktual Economizer mengalami penurunan yang signifikan dari efektivitas Desainnya yaitu Persentase Penurunan sebesar $18 \%$.

Adanya penurunan Nilai Koefisien perpindahan panas keseluruhan dan efektivitas disebabkan oleh adanya pengerakan (scaling) pada pipa yang mengakibatkan konduktifitas termal menurun.

Adanya rugi-rugi yang disebabkan oleh pengerakan dapat dibuktikan dengan perhitungan presentase pengerakan sebesar $2.26 \%$

\section{DAFTAR PUSTAKA}

Karmin dan Ginting, M. 2012. Analisa Peningkatan Kekerasan Baja Amutit Menggunakan Media Pendingin Dromus. Jurnal Austenit Jurusan Teknik Mesin. Vol.4. No.1.Hal 20.

Donny, Komunitas Metalurgi "Teknologi dan Proses Manufaktur Pipa" Hal. 55. Jakarta: Entry Donny Publisher, 2009.

Handbook American Standard Testing and Material. ASTM A106 Standard Specification for Seamless Carbon Steel Pipe for HighTemperature Service. (2012)

Yogantoro, A. 2010. Penelitian Pengaruh Variasi Temperatur Pemanasan Low Tempering, Medium, Tempering dan High Tempering Pada Medium Carbon Steel Produksi Pengecoran Batur-Klaten Terhadap Struktur Mikro, Kekerasan dan Ketangguhan (Toughness), (Skripsi). Jurusan Teknik Mesin Fakultas Universitas Muhammadiyah Surakarta. Surakarta

Widyatmadji. 2001. Pengaruh Perlakuan Panas Nornalisasi Terhadap Sifat Mekanik Dan Struktur Mikro Baja IK3816AT Untuk Aplikasi Casing dan Tubing Spesifikasi. (Skripsi). Universitas Indonesia Jakarta.

Pudji Hartanto, "Mengenal Sifat Mekanik Baja", (Jakarta: PT. Gelora Aksara Pratama, 2004) Hal. 63.

Ahmad Tarmuji, Metalurgi Fisik Moderen Rekayasa Material 2007, Institut Teknik Sepuluh November, Surabaya.

JIS Specification Z2201. 1998. Test Pieces For Tensile Test For Metallic, Hal.10

JIS Specification Z2241. 1998. Method Of Tensile Test For Metallic.

Van Vlack, H Lawrence. 2000. Ilmu dan Tekonologi Bahan, Diterjemahkan oleh Sariati Djaprie, Edisi kelima. Jakarta: Pt.Gelora Aksara pratama. 